\title{
LA REFORMA DE LA JUSTICIA COMO PRESUPUESTO PARA LOS DERECHOS HUMANOS Y EL DESARROLLO ECONÓMICO, EN ATENCIÓN ESPECIAL A LA JUSTICIA PENAL
}

\author{
Justice reform as a presupposition for human rights and economic development
}

\author{
Sergio J. CUAREZMA TERÁN $N^{1}$ \\ Lea Marina MEZA CÓRDOBA²
}

\begin{abstract}
Sumario:
I. Introducción: Un proceso de marcha y contramarcha II. Crisis y fundamento para su reforma. III. La naturaleza de la reforma de la justicia. IV. Riesgos de la reforma de la justicia en una soberanía limitada. A. El plea bargaining system. 1. La posición del juez en el plea bargaining. B. El retorno de las viejas políticas autoritarias. $V$. Consideraciones finales.
\end{abstract}

Resumen: El trabajo tiene como objetivo analizar la reforma de la justicia como presupuesto para el desarrollo de los derechos humanos y el desarrollo económico, y el impacto de la justicia basada en criterios de naturaleza económica en materia de justicia penal.

Palabra claves: Reforma, naturaleza, desarrollo, acusatorio, inquisitivo, economía, plea bargaining, policía, investigación, autoritario, juez.

Abstract. $y$ : The goal in the present work is to analyze the judicial reforms as a requisite for Human Rights development as well as Economic developments, and the influence in criminal justice by reforms made based under Economic criteria.

Key words: reform, nature, development, criminal adversarial system, inquisitorial system, plea bargaining, police, investigation, authoritharism, judge.

${ }^{1}$ ExMagistrado de la Corte Suprema de Justicia de la República de Nicaragua (marzo 2007 a marzo 2012). Es profesor e investigador de Derecho penal del Instituto de Estudio e Investigación Jurídica (www.inej.edu. ni) y de la Universidad Americana (UAM); Miembro del Grupo de Investigadores Reconocidos del Área de Derecho Penal de la Universidad de Valladolid, España; Miembro del Comité Permanente de América Latina para la Prevención del Delito y Experto del Instituto Latinoamericano de Naciones Unidas para la Prevención del Delito y Tratamiento del Delincuente (ILANUD). E-mail: sergio.cuarezma@inej.net Sitio web: www.sergiocuarezma.com

2 Becaria de la Deutsche Akademische Austausch Dienst (DAAD) para estudiar Master in Public Policy and Good Governance en el Willy Brandt School de la Universidad de Erfurt, Alemania (2013-2015), e investigadora del Instituto de Estudio e Investigación Jurídica (INEJ), Nicaragua. También es Máster en Derecho público por el Instituto de Estudio e Investigación Jurídica (INEJ), Diplomado en Derecho procesal penal con mención en los principios, garantías y reglas constitucionales que fundamenta el sistema acusatorio por la Universidad de Guanajuato (UG), México y el Instituto de Estudio de Investigación Jurídica (INEJ), Postítulo sobre Derechos Humanos y Debido Proceso por la Universidad de Chile, y Licenciada en Derecho por la Universidad Americana (UAM), obteniendo la mención honorifica Cum Lauden. 


\section{INTRODUCCIÓN: UN PROCESO DE MARCHA Y CONTRAMARCHA}

En los últimos años Centroamérica, y en particular, Nicaragua, ha experimentado cambios sustanciales y positivos como, por ejemplo, el paso de la guerra a la paz, y la decisión formal de construir sistemas de vida político sobre la base de los principios básicos de la democracia, la paz, la libertad, el respeto de los derechos humanos y el desarrollo sostenible, a pesar de grandes limitaciones económicas. Esta decisión que ha tomado la región hace imprescindible el continuar trabajando en la dirección del fortalecimiento institucional, el reconocimiento, la promoción y defensa de los derechos humanos y el fomento de la gobernanza. Para ello además, debe tenerse en consideración las transformaciones que ha experimentado el mundo que obliga a la región a su integración para afrontar estos retos.

Así, los pueblos del istmo han optado con determinación por un nuevo orden construido en torno a la no confrontación, cuyo objetivo final es alcanzar la democracia con desarrollo social y justicia para el mayor número de personas. Este contexto, generado en 1990, creó ciertas condiciones que podrían desembocar en el surgimiento de una cultura política regional que tiene como principales rasgos característicos la pacificación, la democratización, la transformación de instituciones democráticas, todo esto dentro de una visión de integración regional. La participación de la sociedad organizada en la región juega un rol estratégico y fundamental en el proceso de transformación del Estado, en la creación, promoción y gestión de las políticas públicas y el diseño del sistema de vida político, ya que a través de ella se canaliza el interés en la construcción de una sociedad democrática y la reconstrucción del Estado para promover y mejorar la participación de la misma, es decir la gestión en los intereses colectivos desde el marco de la ciudadanía.

No obstante, y a pesar de todo este esfuerzo, no se han superado las contradicciones económicas y sociales, la pobreza ha aumentado, la iniquidad y la violencia social no han desaparecido, aunque siempre se explicaron como un producto de la ausencia de regímenes democráticos. También, y con gran preocupación, hay que advertir que algunas de las características de los gobiernos del pasado no han desaparecido, aunque no existen dictaduras ni regímenes militares, en la región se destaca una fragilidad y el incumplimiento sistémico del Estado de derecho, la interrupción de regímenes constitucionales, fraudes en los procesos electorales, persecución política, tendencia a la exclusión de las personas en la actividad pública, el desmantelamiento de la sociedad civil, y el control absoluto de las funciones del Estado por el Poder ejecutivo, suprimiendo la división de poderes que cumple, en un Estado de derecho republicano, la función de pesos y contrapesos, todo esto, originando una desagradable escena de degradación de dicho modelo de Estado en un Estado de policía. En consecuencia, las personas tienen muy poca injerencia en los temas públicos, como que si luego de elegir hubieran delegado a los funcionarios sus derechos políticos, lo que hace que las grandes mayorías queden de nuevo excluidas de la esfera del poder y de los espacios de tomas de decisiones, contrario a la idea de participación democrática, con la cual se dieron los primeros pasos a la democratización de la región, y de Nicaragua.

En este proceso de marchas y contramarchas, la región, y Nicaragua, debe concentrar su energía de forma estratégica en promover el aseguramiento de las condiciones básicas de vida para el ciudadano (seguridad humana), la erradicación de la pobreza, fortalecer el desarrollo participativo, propiciar la creación de espacios de democratización, el reconocimiento y tutela de los derechos fundamentales de las personas y la creación del Estado de Derecho y sus principios: supremacía de la ley, legalidad administrativa, jerarquía norma- 
tiva, separación de poderes, tutela de los derechos humanos y control constitucional. Los esfuerzos dirigidos hacia la creación y fortalecimiento de las condiciones para el respecto de estos principios del Estado de derecho significarían el cimiento para lograr un desarrollo integral, ya que éstos permitirían ofrecer condiciones para la gobernanza y la estabilidad en el proceso democrático que actualmente vive la región, y Nicaragua. En aspectos concretos, igualmente implica generar la confianza para la inversión privada como actor importante en el fortalecimiento económico de los países de la región.

En esta línea de pensamiento, la promoción del Estado de Derecho constitucional permite a los sectores menos favorecidos o vulnerables la reivindicación y defensa de sus derechos y libertades con la promoción de la seguridad jurídica, producto de la garantía de la independencia de la justicia y la no concentración del poder. Por tanto, se deben aunar esfuerzos para identificar y aplicar para las próximas décadas una estrategia para fortalecer y profundizar el proceso de construcción o transformación del Estado de derecho, la participación ciudadana y los espacios para el diálogo democrático de carácter real y horizontal, y no formal y vertical.

\section{CRISIS Y FUNDAMENTO PARA SU REFORMA}

La solidez de las instituciones de justicia y del Estado de Derecho, en cualquier país, constituyen la base del buen funcionamiento de las instituciones políticas y de los procedimientos democráticos. Hay un vínculo axiológico y práctico entre la calidad del Estado de Derecho y la estabilidad política y el desarrollo económico y social de la sociedad. Esta correlación de las sociedades y una creciente expectativa que se vincula con estándares de mayor acceso a los sistemas de justicia y de resolución de conflictos, es un derecho a la satisfacción de expectativas de derechos y garantías de la población. Hoy día, el desarrollo debe sustentarse en mayores niveles de equidad y de acceso de todas las personas a las oportunidades. Estas condiciones de equidad, participación y seguridad, suponen la existencia de instituciones públicas fuertes, ágiles, transparentes y eficaces, especialmente de la justicia, pero una independencia e imparcial, un árbitro que pueda hacer respetar las reglas (previas) del juego democrático.

En este sentido, la justicia (y su reforma) viene ocupando, aunque con lentitud, un plano importante dentro de los temas políticos e institucionales de la región. La razón de ello es evidente, la región no había enfrentado con la profundidad requerida y, por tanto, el tratamiento debido a la cuestión de la justicia, la cual ha evolucionado muy lentamente en el último siglo. Para el profesor Ramón de la Cruz Ochoa:

"la desigualdad entre desarrollo económico y político, incluso institucional con la organización de la Justicia ha contribuido al agotamiento y deterioro de las estructuras y procedimientos judiciales, y a la llamada "crisis" de la que tanto se habló en la postrimería del siglo XX". ${ }^{3}$

Esta crisis de la justicia y su reforma se manifestó en un proceso mundial de cambios y transformaciones de los sistemas políticos, por ejemplo, el desmantelamiento de los regímenes socialistas, la aparición de un nuevo orden político y el nacimiento de la globalización, en la cual, la economía y las finanzas ocupan una atención singular. Estos cambios obligaron

\footnotetext{
${ }^{3}$ DE LA CRUZ OCHOA, Ramón, "Reforma de la Administración de Justicia en América Latina”, Conferencia Pronunciada en el Congreso de la Asociación Americana de Juristas celebrado en La Habana, Cuba, 18 de octubre de 2000 .
} 
que el tema de la justicia, pasara a considerarse no "sólo factor de desarrollo", sino "destinada a impulsar el desarrollo". Así, la justicia, y particularmente la penal, que en su inicio postulaba como fundamento para su reforma la promoción y la tutela de los derechos humanos, comienza a verse en estrecha relación con el desarrollo económico (justicia y economía), como un presupuesto para en la seguridad de las inversiones económicas, financieras y empresariales, y por tanto, asegurar las grandes inversiones extranjeras directas en la región. La justicia y su importancia, pasa pues, de un interés "local" a un interés "regional", y, su fundamentación del plano de los "derechos humanos", al plano predominantemente "económico".

\section{LA NATURALEZA DE LA REFORMA DE LA JUSTICIA}

En el contexto de este proceso complejo de reforma de la justicia,

"no debe sorprendernos que las reformas económicas, estructurales que se vienen llevando a cabo en muchos países en desarrollo impulsan a los de la región a abordar la reforma de la justicia como complemento necesario a la reforma económica y no como en lo que en realidad debe ser, un camino para el mejoramiento del Estado de Derecho y de la democracia y de mayor respeto para los derechos humanos",

como expresa Ramón de la Cruz Ochoa ${ }^{4}$ Lo cierto es que ambas categorías merecen tutelas, los derechos humanos y la seguridad de las inversiones, cada cual con sus matices, la primera, por ser fundamento vital del Estado de Derecho, y la segunda, para la promoción de las inversiones y el consecuente desarrollo económico de la región. Hay un acuerdo común respecto a que el proceso de liberación económica que vive la región, y Nicaragua, plantea relevantes exigencias de reformas legales e institucionales, encaminadas a asentar estratégicamente esos procesos y, a la vez, para hacer frente a las múltiples desigualdades sociales heredadas y provocadas por modelos económicos desprovistos de un perfil humanístico en su esencia de funcionamiento.

Para De la Cruz Ochoa, ${ }^{5}$

"la reforma de los sistemas de justicia ha sido estimulada en gran medida por actores internacionales económicos, países desarrollados donantes y otras instituciones internacionales. Estas ocurren en el marco de la modernización del Estado y se ofrecen como argumento los vínculos estrechos entre crecimiento económico y sistemas legales y de justicia eficaces, informalizados, accesibles, previsibles, entre otros. Esta cruzada internacional por la transformación legal y judicial llevada a cabo por muchas agencias internacionales no tiene en cuenta las justificaciones y el sentido político de la reforma legal y de la administración de justicia judicial que deben tener en la región y sólo su preocupación económica asume y promueve las reformas como cambios técnicos necesarios para una modernización adecuada del Estado y un crecimiento económico guiado por el mercado".

Esta tendencia de la reforma judicial desarrollada exclusivamente con lineamientos técnicos y económicos, como lo plantea De la Cruz Ochoa, sin atender el tema de los derechos hu-

\footnotetext{
4 Idem.

5 Idem. 
manos, debe de generar una atención y preocupación particular en la sociedad regional, y nacional. Es decir, si el enfoque de la reforma de la justicia está orientada a lo económico, sin duda, este modelo de justicia (economicista) determinará, queramos o no, el contenido de la reforma dela justicia, el modelo y la función de las instituciones de la administración de justicia y su normativa orgánica, sustantiva y procesal. Esto sucedió en el modelo económico colonial, que para su seguridad estableció el modelo de justicia penal inquisitivo (europeo continental), como expresión de dominio hegemónico de aquel momento histórico. Por su parte, hoy, el modelo de mercado económico de la globalización impone su propio modelo de justicia penal, el acusatorio (con un fuerte componente inquisitivo).

Ejemplo de esa visión economicista y técnica de la reforma de la justicia, se pone de manifiesto en un excelente estudio del Programa de Naciones Unidas para el Desarrollo sobre la Seguridad Jurídica e Inversiones realizado en Centroamérica y Panamá. ${ }^{6}$ Esta investigación que trata, entre otras cosas, sobre el concepto de seguridad jurídica, sistema de registro, inseguridad ciudadana e inversión, expropiación e indemnización e inversión, protección a la propiedad intelectual e industrial e inversión extranjera, legislación ambiental y ordenamiento territorial ante la inversión extranjera, clima de negocios e inversión, competitividad e inversión, establece que

"para empresarios de sesenta y nueve países, son importantes para la inversión económica la credibilidad del Estado, la previsibilidad de las normas y de las políticas, las percepciones sobre la estabilidad política y seguridad de la propiedad, la relación Estado-Empresas, la incertidumbre creada por la ineficiencia del gobierno en la prestación de servicios, la importancia de la criminalidad, la confianza en la aplicación de la ley por la justicia, las trabas burocráticas y la importancia de la corrupción".

En este sentido, Umaña, ${ }^{7}$ recuerda que estudios similares del Banco Mundial han encontrado causalidades entre la credibilidad y estabilidad de los sistemas jurídicos y las variaciones del crecimiento del PIB per cápita.

No existe ninguna duda que la reforma del sistema de justicia, en especial la penal, debe garantizar la seguridad jurídica para el desarrollo económico y además, asegurar que las normas no sólo se apliquen, sino que exija su cumplimiento efectivo. En este sentido, el valor de la justicia concebido como aplicabilidad o exigibilidad permite identificar violación al orden jurídico y sancionar al transgresor o reparar el daño a favor de la víctima. Sin embargo, la reforma de la justicia también es vital para la realización efectiva de la democracia y los derechos humanos -no sólo para la creación de un ambiente seguro para los negocios-, recogidos en buena parte de las Constituciones Políticas de la región, pero sin posibilidad de realizarse. Los derechos humanos, como expresa Zaffaroni ${ }^{8}$, deben ser, ante todo, "garantizados por los gobiernos y, en especial, por los poderes judiciales nacionales. Los organismos

\footnotetext{
${ }^{6}$ Programa de las Naciones Unidas para el Desarrollo. Seguridad Jurídica e Inversiones. Acceso a la Justicia en Centroamérica y Panamá, San José, Costa Rica, 200o, p.15.

7 UMAÑ, Mario, "Inversión Extranjera Directa en Centro América: el rol de la seguridad jurídica”, Marzo, 2002, p. 22. Documento en proceso, recuperado de: $h t t p: / / w w w . i n c a e . e d u / e s / c l a c d s / p u b l i c a c i o n e s / p d f / c e n 443$. $p d f$

8 CUAREZMA TERÁN, Sergio, La Posición del Juez en Nicaragua. La Administración de Justicia como garante de los Derechos humanos en Nicaragua, Managua, Imprenta UCA, 1996, p. 13.
} 
internacionales, políticos o jurisdiccionales, no son más que reaseguros que operan cuando fallan las garantías nacionales, pero jamás pueden sustituir a éstas".

No hay duda que la seguridad jurídica exige un sistema funcional, expedito, transparente e imparcial, sin embargo, no hay acuerdo en qué consiste la imparcialidad y la rapidez del sistema de justicia. El estudio sobre la Seguridad Jurídica e Inversión ${ }^{9}$ pone de manifiesto el interesante dato que

"la cultura jurídica centroamericana popular - no así la del sector privado, aparenta inclinarse por cierta ausencia de orden y rapidez siempre y cuando se asegure cierto nivel de justicia social, mientras que la misma cultura en los países desarrollados (y principales sedes de las empresas inversionistas) prefieren arriesgarse a la injusticia antes que soportar el desorden y el atraso judicial".

\section{RIESGOS DE LA REFORMA DE LA JUSTICIA EN UNA SOBERANÍA LIMITADA}

La región pasa por un momento de transnacionalización de sus Estados y cada vez son más dependientes. Sus soberanías están limitadas. Mediante estos procesos, señala el profesor de la Universidad de Western, Ontario, Andrés Pérez Baltodano, ${ }^{10}$

"el Estado transfiere importantes cuotas de poder a los centros transnacionales alrededor de los cuales se organiza la globalización, adquiriendo niveles de inmunidad ante las sociedades de estos Estados. Todo ello deteriora los poderes nacionales o bien, anula todo intento de construcción de un Estado originado del consenso contractual de la sociedad. La pérdida del poder de los Estados es parte de la globalización, reduce a los actores nacionales a la impotencia frente a los problemas reales que se plantean en sus comunidades".

Para Zaffaroni, ${ }^{11}$ la globalización, "como momento de poder mundial consecuente de la revolución tecnológica, presenta una serie de contradicciones, pero el elemento más notorio es la pérdida de poder por parte de los Estados nacionales".

Bob Jessop citado por Andrés Pérez Baltodano, ${ }^{12}$ plantea que

"el aparato estatal transnacionalizado sufre una pérdida progresiva de unidad en términos de la coherencia vertical entre los diferentes niveles de organización, y de coordinación horizontal entre las diferentes áreas de actividad estatal. En estas condiciones, el Estado pierde capacidad para promover la integración social y la formación de identidades políticas nacionales. La transnacionalización del Estado en la región, además, obstaculizará las posibilidades de desarrollo de verdaderas sociedades civiles fundamentadas en estructuras efectivas de derechos ciudadanos. La transnacionalización del Estado disminuye significativamente la capacidad de la política democrática y de la participación política organizada como fuerzas constitutivas de la Nación. La pérdida de poder local crea normas y valores determinados por la racionalidad e intereses del poder transnacional que

\footnotetext{
9 Op. cit., nota 4, p. 81.

10 PÉREZ BALTODANO, Andrés, "El futuro de las identidades políticas de América Latina”, Confidencial. Semanario de Información y Análisis, no. 233, 2001, p. 1.

${ }^{11}$ ZAFFARONI, Raúl, "El Curso de la Criminología”, Revista de la Asociación de Ciencias Penales de Costa Rica, no. 18, 200o, pp. 10-11.

${ }^{12}$ PÉREZ BALTODANO, Andrés, op. cit., nota 8, p. 2.
} 
condicionan a los estados nacionales debilitados e inducen a las sociedades a aceptarlos como parte del progreso".

Un ejemplo, es la exigencia de la reforma de la justicia. Muchas de las reformas en materia de justicia, y en particular, de la penal, fueron condicionadas de forma exógena (sin perjuicio de la necesidad de reformarlas), y no se construyeron desde las particulares necesidades y contradicciones de la sociedad.

En esa línea de pensamiento apuntada, podemos observar que la transformación regional de la justicia, y en particular la de Nicaragua, estuvieron inducidas o condicionadas por los países centrales o industrializados para optar a un nuevo modelo de justicia y, por su coste, a menor acceso a la justicia, nos referimos al Common Law. Este sistema de tradición anglo-sajona, como advierte Umaña, ${ }^{13}$ "desarrollado en principio en el Reino Unido y traslado posteriormente a Estados Unidos, Canadá, Australia, Nueva Zelanda, está basado en el precedente judicial, más que la legislación escrita. Se contrasta con el sistema de la tradición del Derecho Civil o Tradición Romano Germánica donde la fuente primaria del derecho es la norma escrita".

\section{a) El plea bargaining system}

Este sistema, injertado en la justicia de la región, y con gran profundidad en el nicaragüense, ha instaurado una "justicia rápida" (fast justice) a través del plea bargaining system, más pudorosamente traducido como negociación. ${ }^{14}$ En el desarrollo del trabajo, advertimos que determinar la naturaleza de la reforma nos permite a la vez determinar el impacto que esta tiene en las instituciones y cuerpo normativo que reforma o crea, este es el caso de la denominada justicia negociada, que privatiza de la justicia.

El plea bargaining system (regateo de la justicia), de tradición anglo-norteamericana, es consecuente a la naturaleza economicista de la reforma de la justicia, se excluye al juez del conflicto, igual que en el mercado libre que no hay agentes reguladores, y pone en manos de particulares (fiscal y defensor) la decisión del caso penal que debería estarlo en la figura del juez constitucional. En este sentido, según De Diego Díez, ${ }^{15}$ para los econometricians el plea bargaining es un "mal necesario" y propugnan su mantenimiento como algo deseable.

"Para ellos el proceso penal no es sino un sistema de mercado, un método de distribución de recursos escasos, y dan por supuesta la imposibilidad de los operadores judiciales de varia el quantum de los recursos disponibles. A partir de estas premisas afirman -en armonía con la concepción de libre mercado propugnada a nivel económico- que la intervención "reguladora" de la autoridad publica, identificada en el proceso penal con la decisión del Juez sobre la pena, puede dar buenos resultados solo si el "precio" fijado por la autoridad competente coincide con el que las partes contratantes han convenido"16

\footnotetext{
${ }^{13}$ UMAÑA, Mario, op. cit., nota 5, p. 28.

14 ZAFFARONI, Raúl, op. cit., nota 9, p. 15.

${ }^{15}$ DE DIEGO DÍEZ, Luis Alfredo, La plea bargaining de los EE.UU. En Justicia Criminal Consensuada (Algunos modelos del derecho comparado en los EE.UU., Italia y Portugal), Valencia, Tirant lo Blanch, 1999 , p. 61.

${ }^{16}$ Ibidem, pp. 61-62.
} 
Feeley, citado por De Diego Díez ${ }^{17}$ la compara

"con los supermercados en los que los precios de los distintos productos están claramente fijados y etiquetados [...]. En un supermercado, los clientes pueden quejarse de los precios, pero raras veces regatean [bargain] para que se les rebaje"

El regateo promueve procedimientos "reacios a los preceptos éticos, que nada tienen que ver con la justicia ni la equidad", como expresa José Carlos Barbosa Moreira ${ }^{18}$, que la reforma pretendía eliminar del viejo modelo inquisitorial.

Este sistema de justicia, llamados por algunos, justicia mil por horas o la macdonalización de la justicia, "encierra un peligro en la pretensión de implementar formas rápidas de condenación, que pretenden que nada quede por escrito, creando la ilusión expeditiva y pragmática". ${ }^{18}$ Para Zaffaroni, ${ }^{19}$ en la investigación comparativa de la investigación, Los derechos fundamentales en la instrucción penal en los países de América Latina, "la publicidad con que se divulgan estos modelos en la región es preocupante, porque puede ser fácilmente vendible a los políticos preocupados por las demandas públicas de una justicia penal más rápida". Para Zaffaroni ${ }^{20}$ estas propuestas, dadas las características de la región, "no llevarían más que a un proceso penal destinado a la rápida y barata condenación de pobres, perfectamente compatible con el modelo economicista incompatible con la dignidad de la persona”.

En los foros académicos y científicos de los Estados Unidos esta institución es duramente criticada, a tal punto que un eminente Magistrado no vaciló en llamarle al plea bargaining un "sórdido proceso" y John Langbein, ${ }^{21}$ de la Universidad de Chicago ha llegado a contrastarla con el derecho medieval europeo sobre la tortura, "las semejanzas entre el sistema moderno de plea bargaining y el antiguo sistema de tortura judicial son muchas y escalofriantes". Asimismo, indica Langbein ${ }^{22}$ que el plea bargaining es un "procedimiento sin juicio establecido para declarar culpables y para condenar a personas acusadas de delitos graves. Sin alguien busca en la Constitución de los EE.UU. algún fundamento para el plea bargaining, buscará en vano. En su lugar encontrará, una garantía opuesta, la garantía del juicio previo".

En este sentido, Zaffaroni ${ }^{23}$ expresa que el plea bargaining se convierte fácilmente en una fuente de extorsión que remplaza a la tortura:

"Quien carece de defensa de calidad no tiene otro recurso que admitir lo que se le ofrece

17 Ibidem, p. 52.

${ }^{18}$ BARBOSA MOREIRA, José Carlos, “La Transacción Penal Brasileña y el Derecho Norteamericano", Revista de la Asociación de Ciencias Penales de Costa Rica, no. 17, 200o, p. 52.

${ }^{19}$ Idem.

${ }^{20}$ Idem.

${ }^{21}$ LANGBEIN, John H., "Tortura y plea bargaining”, en Mayer, Julio y Bovino, Alberto (comps.), El procedimiento abreviado, Buenos Aires, Del Puerto, 2001, p. 9.

${ }^{22}$ Idem.

${ }^{23}$ ZAFFARONI, Raúl, "América Latina: Análisis regional, proceso penal y derechos humanos: Códigos, principios y realidad", en Luzón Peña, Diego-Manuel et al. (dirs.), Documentos penales y criminológicos (DPC), vol. I, Hispamer, 2001, p. 352. 
en la negociación o regateo, pues de lo contrario se le amenaza con un pena mucho más grave. De este modo se logra reducir el número de presos preventiva, puesto que se los condena a todos rápidamente". Además se trata de otro recurso que llena otro requisito fundamental podrá la selectividad estructural del poner punitivo: perjudica sólo a quienes tienen menores recursos; el resto puede incluso beneficiarse con él. En tercer lugar, los jueces pueden seguir ejerciendo el manejo de la prisión preventiva como pena, aunque ya a modo de pena formal".

Para DeDiego Díez, 24 "la plea bargaining es tan frecuenteen el sistema criminal norteamericano que mediatiza su organización hasta tal punto, apoyándose en los criterios de Newman y Anderson, que el orden del día del Tribunal, el personal judicial, y otros recursos están determinados de antemano dando por hecho que habrá un alto índice de declaraciones de culpabilidad". El Tribunal Supremo de los Estados Unidos, en el caso Santobello v. New York (404 U.S. 257, 260, [1971]), estableció que este tipo de acuerdo "representa un componente esencial de la administración de justicia.

La fundamentación que se aduce para justificar la validez de esta institución es la "eficacia". Entre ellas se menciona, como señala De Diego Díez, ${ }^{25}$

“el enorme número casos que el Ministerio Público debería afrontar, el costo de cada proceso para el Estado, la oportunidad de no malgastar los recursos económicos destinados al servicio judicial, la necesidad de concentrar los esfuerzos de la acusación en los casos de provocan mayor alarma social, entre otros".

En este sentido, como plantea De Diego Díez, ${ }^{26}$

"parece que beneficia a todos los involucrados en la justicia penal, desde el acusado, su defensor y el fiscal. Por ejemplo, el acusado evita gastos, retrasos e incertidumbres, así como el riesgo de una condena más grave (aunque sea inocente) que la que de hecho se le impone; el abogado defensor obtiene sus honorarios con menores esfuerzos y economizando tiempo. Sin embargo, esta tentadora perspectiva empuja fácilmente al defensor a convencer a su cliente de que se declare culpable".

ALSCHULER, citado por De Diego Díez, ${ }^{27}$ refiriéndose a este tema, expresa que

"todo el actual sistema de justicia criminal estadounidense parece diseñado, en suma, para inducir al abogado defensor a adoptar la siguiente máxima: en caso de duda, entrégale (cop him out)... y negocia. Al Ministerio Público le permite, con la resolución "contratada" del proceso, controlar la carga de trabajo y además, en caso se llevaran a jurado, la condena sería incierta. El Estado, determina la culpabilidad muy económicamente porque no tiene que cumplir la obligación constitucional de aportar pruebas".

\footnotetext{
${ }^{24}$ DE DIEGO, Díez, Luis Alfredo, op.cit., nota 13, p. 54.

${ }^{25}$ Ibidem, p. 55.

${ }^{26}$ Ibidem, p. 18.

27 Ibidem, p. 59.
} 
El plea bargaining altera el sistema de legalidad y su vigencia (y, en consecuencia, el de seguridad) vinculado al Estado de derecho, en el cual, la justicia se aplica, no se negocia. En este tema lo que está en juego es la respuesta jurídica ajustada a la legalidad, incompatible con la disponibilidad del proceso penal en manos de particulares (fiscal y defensor). No hay que olvidar que la misión constitucional del Poder judicial de la mayoría de los países de la región, y del nicaragüense, es la tutela de los derechos humanos mediante la aplicación (y no la negociación) de la ley (art. 158 y 160 Constitución Política). Conforme a este mandato constitucional los particulares, en virtud del monopolio estatal, no pueden ni deben disponer del Derecho penal, ni de la consecuencia jurídica penal, ya que éste se aplica (o debería aplicarse) sólo por jueces y tribunales constitucionales en el marco de un proceso penal. En el Derecho penal la descripción de las conductas delictivas (tipos penales legales) formalizan y delimitan la justicia, pero ésta sólo puede realizarse en el proceso penal, debidamente desarrollado y con el debido proceso legal, sólo así se puede "condenar y remover la presunción de inocencia".

No cabe duda que la negociación conduce a la privatización del proceso penal (de la justicia penal), es, como expresa Amodio, citado por De Diego Díez, ${ }^{28}$ "una verdadera y propia exaltación de la autonomía de las partes". Este criterio encuentra su fundamento conceptual en la existencia de una relación horizontal entre partes, de la que se originan derechos y obligaciones. El fiscal y el defensor cuando "negocian" un delito por otro o la responsabilidad del acusado o un privilegio a cambio de una información, están realizando un "negocio de carácter privado". Este toma y data, Brown, citado por De Diego Díez $z^{29}$ "expropia a las partes de sus específicos papeles y las reduce, en la mejor de los casos, al nivel de mercaderes; en el peor, a intrigantes. Jueces y abogados olvidaran su deber de contribuir a la búsqueda de la verdad, mientras los representantes de la acusación y los defensores no se dedicaran a preparar el proceso penal con el interés necesario".

No es posible pues, conciliar la legalidad (ley escrita) con la negociación (sistema no escrito). Este tipo de justicia (de regateo) supone, en expresión del profesor norteamericano Friedman, negociar a la sombra de la ley.

\section{LA POSICIÓN DEL JUEZ EN EL plea bargaining}

En Nicaragua en el año 2004, se llevó a cabo una importante investigación comparada por profesores e investigadores del Instituto de Estudio e Investigación Jurídica, Rosario Alvarado Chacón y Jorge Luis Morales García, jueces del Poder Judicial costarricense, sobre La Negociación en la Justicia Penal: La Posición del Juez. Estudio Comparado (Alemania, Costa Rica, Estados Unidos, Italia y Nicaragua)

El trabajo presenta análisis sobre: el plea bargaining system de los Estados Unidos de Norteamérica, modelo que sirvió de base a otros institutos de los sistemas de tradición jurídica continental europea como son los supuestos del patteggiamento italiano, del procedimiento abreviado costarricense y del acuerdo en el Código procesal penal nicaragüense. Igualmente comprende la oportunidad reglada en la ordenanza procesal penal alemana, en el Código procesal penal costarricense y la prescindencia de la acción penal en el nicaragüense.

\footnotetext{
${ }^{28}$ Ibidem, p. 75 .

${ }^{29}$ Ibidem, p. 50. 
La investigación hizo un análisis comparativo de legislaciones europeas y anglosajonas, a fin de determinar el papel hegemónico que las visiones de los países desarrollados ejercen sobre aquellos que, como las naciones de Costa Rica y Nicaragua, presentan un esencial interés, sobre todo, de carácter económico, para esos centros de concentración de poder. Con esto se espera extraer conclusiones válidas y claras respecto al tema central de la investigación, el rol del juez en la justicia penal negociada, lo cual requirió, además, para su enriquecimiento de fuentes doctrinarias de legislación, jurisprudencia y aportaciones críticas hechas por los autores de la investigación desde la función de la judicatura.

La investigación establece que ésta institución no puede verse en forma aislada de los factores que condicionan la reforma penal en Centroamérica y que también explican, en gran medida, el grado de uniformidad de las legislaciones, como de los organismos internacionales que impulsan su gestión. En Nicaragua, pese a que no existía una necesidad apremiante para instaurar una reforma penal en virtud de la mora judicial, ${ }^{30}$

"los índices de retardo de justicia en causas con detenidos había disminuido del 12\% en diciembre de 1999, al 4\% en diciembre del 2000 en Juicios Ordinarios; y del 50\% al 7\% en el mismo período en Juicios Especiales de Adolescentes."

como era el caso de otros países de la región, en cuenta Costa Rica; si contribuía a los abanderados de la gestión de la reforma, el contar con un Código de instrucción criminal con más de un siglo de vigencia; sin embargo, son las razones ideológicas las que pesaron más en impulsar la reforma y que en el tipo de reforma que se impulsó.

Respecto al rol del juez en el acuerdo nicaragüense, la investigación expresa que la similitud o proximidad del sistema nicaragüense con el angloamericano, le hace acreedor de las principales críticas de aquel, abonadas con las circunstancia de que la importación de este cuerpo extraño a la realidad socio-jurídica nicaragüense provocará no pocos contrasentidos estructurales, como pueden ser sus objeciones de constitucionalidad.

Uno de los principales cuestionamientos que se puede realizar a este tipo de instituto procesal es su falta de transparencia. La intervención del juez nicaragüense en el procedimiento de acuerdo es nula, su aparición se da cuando este ya está logrado, cuando todo se ha discutido. La función o rol del juez nicaragüense en este procedimiento (en el caso llegue a su conocimiento, pues se puede dar de facto en el proceso de investigación) es de mero fedatario de una situación en donde no tuvo ninguna participación y, consecuentemente, ninguna posibilidad de control.

La sentencia que con base en un acuerdo de estos pudiese dictar el juez de la causa, no puede ser otra que condenatoria, pues tendría como base fáctica el hecho confesado y estaría vinculada por el acuerdo de las partes en cuanto a las consecuencias punitivas. Así las cosas, la investigación concluye que la participación del juez nicaragüense en el trámite del acuerdo es prácticamente nula, desprovista de cualquier posibilidad real de ejercer un control garantista de los derechos fundamentales del imputado.

${ }^{30}$ Memoria de la Sala de lo Penal de la Corte Suprema de Justicia (1996-20oo), Managua, Corte Suprema de Justicia de la República de Nicaragua, 2001, p. 80. 


\section{A) EL RETORNO DE LAS VIEJAS POLÍTICAS AUTORITARIAS}

También, estas reformas de corte economicistas, han empujado a la región a importar políticas puramente represivas, como, por ejemplo, la denominada "ley y orden" o "tolerancia cero". Este tipo de política tiene un grave impacto en el detrimento de los derechos humanos, especialmente de los derechos fundamentales del debido proceso a favor de la persona imputada en la fase de investigación penal, controlada legal y fácticamente por los órganos represivos de seguridad o policial.

Esta política punitiva, fundamentada en golpear duro a los delincuentes y sin garantías, atribuye mayores atribuciones a la policía para la "lucha" o "represión" contra el delito, en detrimento de los derechos y garantías de las personas, incluyendo a las sometidas a investigación. En palabras de Eduardo Galeano, 31 "la represión plan bestia, pócima mágica elogiada por los medios de comunicación, se descarga generalmente con saña sobre los sectores marginales y otras minorías".

Estamos, conforme a esta política, producto de la naturaleza económica de la reforma de la justicia penal, retornando a la vieja concepción de la policía autoritaria del siglo XIX, contexto en el cual esta agencia represiva se originó, primero, como institución de carácter urbano y, segundo, con el objeto de cuidar o proteger, según "la enorme concentración de riqueza y, a la vez, cuidar la "concentración" de la miseria". ${ }^{22}$ Por esta razón, la visión del criminólogo Carlos Alberto Elbert, ${ }^{33}$ no deja de ser acertada a futuro, o a lo menos sugerente, cuando expresa que la vida urbana del siglo XXI, más que vida,

"será una pesadilla insufrible; mayores zonas marginales, personas sin documentación ni trabajo estable, pagando salteado sus alquileres y servicios. Esta situación hace más fácil criminalizar a los excluidos, tanto en el plano individual como familiar o colectivo. Dada la evidente procedencia social de los protagonistas sociales, la selección de sospechosos y diferentes resulta extremadamente obvia y los grupos considerados peligrosos pueden ser seleccionados con sólo observar las multitudes por las calles".

La naturaleza económica de la reforma de la justicia de la penal, permite entonces, comprender el papel que le toca jugar a instituciones como, por ejemplo, la policía, un rol, en este caso, de cuidar la libre circulación de bienes y capitales, una policía no como "medio", sino como "fin" de la economía globalizada, de la tutela del tráfico de capital y mercancía en y entre territorios, y no como una institución para la prevención del delito y garante de la seguridad ciudadana. Ahora bien, la policía para garantizar esta misión, proteger el capital de la "concentración de la miseria", necesita de suficientes garras, estas no son otras que las extensa facultades que la legislación procesal penal le confiere a dicha institución en detrimento de la seguridad de las personas, sobre todo de aquellas sometidas a la pobreza y

\footnotetext{
${ }^{31}$ GALEANO, Eduardo, Patas Arriba. La Escuela del Mundo al Revés, México, Siglo XXI, 1999, p. 88.

32 ZAFFARONI, Raúl, "Proceso Penal y Derechos Humanos: Códigos, Principios y Realidad", El Proceso Penal. Sistema Penal y Derechos Humanos, México, Porrúa, 20oo, pp. 3-24, p. 9; CUAREZMA TERÁN, Sergio et al., "La Policía en el Estado de Derecho Latinoamericano: El Caso Nicaragua", en Ambos, Kai et al. (coords.), La Policía en los Estados de Derecho Latinoamericanos. Un proyecto internacional de investigación, Bogotá, Ediciones Jurídicas Gustavo Ibáñez C., Ltda., 2003, p. 423.

${ }^{33}$ ELBERT, Carlos Alberto, "El control sin Estado y sin políticas criminales en la América Latina globalizada", en Luzón Peña, Diego-Manuel et al. (dirs.), Documentos penales y criminológicos (DPC), vol. I, Hispamer, 2001, p. 565.
} 
marginalidad. Así, podemos apreciar una policía que controla, sin ningún tipo de auditoría judicial, la fase de investigación en el proceso penal (acusatorio) para la construcción de un caso penal.

En la investigación realizada por ILANUD en Latinoamérica (2007), bajo la dirección científica del profesor Zaffaroni, sobre Los derechos fundamentales en la instrucción penal en los países de América Latina, ${ }^{34}$ en la cual se estudio el caso de Nicaragua, se llegó a comprobar empíricamente las violaciones de los derechos fundamentales de las personas imputadas en la etapa de investigación.

En las conclusiones se presentan hallazgos graves, violaciones propias de un proceso inquisitivo, identificadas en las nuevas legislaciones de corte acusatorio. En la etapa de la instrucción penal practicadas por los cuerpos policiales, se advierte, entre otras cosas, que a los detenidos (imputados) no gozan del derecho a la presencia de un defensor y se encuentran incomunicados; que las declaraciones que brindan los detenidos en la policía en el proceso el judicial no las excluye, les da valor probatorio contaminando la imparcialidad de los jueces, legitimando el modelo materialmente inquisitivo en sede acusatorio; que la policía y el Ministerio Público asumen poderes arbitrarios o incontrolados; también que el hecho de que la detención, custodia y alojamiento del detenido o imputado recaiga en un mismo cuerpo, debilita la defensa del detenido; que respecto al valor procesal de la prueba obtenida ilícitamente, quedó claro que existen en las nomas procesales y practicas judiciales orientadas a salvar las deficiencias en la investigación policial para permitir una valoración positiva de los elementos obtenidos ilícitamente; que estos vicios por parte de la judicatura revela que se ha adoptado a nivel latinoamericano una doctrina jurídica de origen europeo que propicia estados legales de derecho y no estados constitucionales de derecho, privilegiando la seguridad de respuesta por sobre la seguridad jurídica.

Esto vendría a explicar por qué el nuevo proceso penal en los países de la región, y en especial, de Nicaragua, le confiere a la policía un poder extenso en la investigación y además sin control de ningún tipo, mucho menos del judicial, sólo subordinado a la autoridad administrativa, en este caso, del Poder ejecutivo, del cual depende en la mayoría de los casos. Podemos advertir entonces, en esta línea de pensamiento, que establecer o identificar la naturaleza de la reforma de la justicia penal, no solo es necesaria, sino que es vital, porque nos permite comprender cómo y por qué se estructura el actual proceso penal de la región, y en especial del nicaragüense (de modelo acusatorio), de una determinada forma, la función de determinadas institutos procesales y la importación de figuras procesales de otros sistemas jurídicos, como el plea bargaining system.

La reforma de la justicia penal estaba concebida para la defensa de los derechos y garantías de la persona sometida al proceso y la democratización del proceso penal, para esto se apostaba a la derogación del modelo inquisitivo y optar por un modelo acusatorio que representaba mayor garantía que el anterior, así lo expresó la solitaria e importante sentencia número 20/2009 de la Sala de lo Penal de la Corte Suprema de Justicia de Nicaragua:

${ }^{34}$ ZAFFARONI, Raúl, op. cit., nota 17. 
"Uno de los lineamientos centrales que inspiró a la reforma procesal penal en nuestro país, es la de conseguir que en la tramitación de todas las fases del procedimiento penal se respeten los derechos fundamentales o garantías constitucionales de las personas objeto de juzgamiento penal, pues sin lugar a dudas el procedimiento inquisitivo establecido en el código de instrucción criminal derogado se caracterizaba por que se desarrollaba al margen del respeto de estas garantías constitucionales o al menos con una muy reducida aplicación, a pesar de estar consagrados expresamente en la Constitución Política y en los Tratados y Convenios Internaciones suscritos por Nicaragua" (Considerando II)

Sin embargo, lamentablemente esto no fue así, la reforma de la justicia penal, partiendo de nuestra idea, fue concebida para la seguridad de las inversiones económicas y financieras, y por tanto, el diseño de proceso penal nicaragüense de "modelo acusatorio", está orientado a garantizar aquella seguridad globalmente requerida para la protección del capital y el tráfico de la mercancía, no en vano ambas se dan, en similar contexto. Esto explica además, que hayan sido las agencias o instituciones económicas internacionales las que hayan invertido el dinero necesario para tal reforma. No olvidemos el viejo adagio: "quien pone la plata, pone los músicos".

\section{CONSIDERACIONES FINALES}

Todo lo anterior, nos da la sensación, como dice Zaffaroni ${ }^{35}$, “de que todo está al revés y de alguna manera parece que así es, conforme a nuestras pautas todo parece estar al revés", es decir, como dijo Eduardo Galeano ${ }^{36}$ "si Alicia volviera hoy no tendría necesidad de mirar al espejo sino que le bastaría con asomarse a la ventana”.

La justicia es un presupuesto para los derechos humanos y para el desarrollo económico, no dudamos, que esta no solo es factor de impulso, sino factor para el desarrollo de la economía, pero también cierto es que una reforma, como la apuntada, orientada a este último aspecto, para crear condiciones de confianza en la inversión y desarrollo económico de nuestras sociedades, crea un desbalance como el apuntado a lo largo del trabajo, ya que los derechos humanos de la persona quedan fuera del propósito de la misma, expuesta, sin duda, al impacto que supone una justicia diseñada exclusivamente para el impulso de la economía. El reto, es el equilibrio, una reforma para ambos supuestos, para la protección de los derechos humanos de la persona y para garantizar un marco de seguridad a la economía para el desarrollo de la región, y de Nicaragua.

El desafío es sin duda mayúsculo, hacer que la reforma de la justicia se oriente, en consecuencia, a transformar las bases de legitimidad sobre las cuales funciona. Ello supone un cambio sustancial en las relaciones con la sociedad, un "encuentro con la persona y su desarrollo", diseñada dentro de una estrategia a largo plazo y dirigida fundamentalmente a producir un cambio en el comportamiento y en la estructura de pensamiento, entre los cuales los sujetos económicos juegan un importante papel. Tal perspectiva constituirá un "cambio cultural" de primera magnitud con respecto a los esfuerzos de la justicia emprendida en la región centroamericana y, en especial, en Nicaragua.

\footnotetext{
35 ZAFFARONI, Raúl, op. cit., nota 31, p. 10.

${ }^{36}$ GALEANO, Eduardo, op. cit., nota 3o, p. 2. 
BIBLIOGRAFÍA

BARBOSA MOREIRA, José Carlos, "La Transacción Penal Brasileña y el Derecho Norteamericano", Revista de la Asociación de Ciencias Penales de Costa Rica, no. 17, 2000, pp. 49-53.

BURGOS LADRÓN DE GUEVARA, J. "La reforma del proceso penal: por un modelo contradictorio", Justicia 2011, no. 3-4, pp.121-132.

DE LA CRUZ OCHOA, Ramón. Reforma de la Administración de Justicia en América Latina. Conferencia Pronunciada en el Congreso de la Asociación Americana de Juristas celebrado en La Habana, Cuba, 18 de octubre de 2000.

CUAREZMA TERÁN, Sergio et al., "La Policía en el Estado de Derecho Latinoamericano: El Caso Nicaragua”, en Ambos, Kai et al. (coords.), La Policía en los Estados de Derecho Latinoamericanos. Un proyecto internacional de investigación, Bogotá, Ediciones Jurídicas Gustavo Ibáñez C., Ltda., 2003, pp. 423- 461.

"El desafío de la justicia”, El PNUD y Nicaragua ante el tercer milenio. Una visión nicaragüense sobre gobernabilidad y desarrollo humano, Managua, 2001, pp. 63-68.

, La Posición del Juez en Nicaragua. La Administración de Justicia como garante de los Derechos humanos en Nicaragua, Managua, Imprenta UCA, 1996.

DE DIEGO DÍEZ, Luis Alfredo. La plea bargaining de los EE.UU. En Justicia Criminal Consensuada (Algunos modelos del derecho comparado en los EE.UU., Italia y Portugal), Valencia, Tirant lo Blanch, 1999.

ELBERT, Carlos Alberto, "El control sin Estado y sin políticas criminales en la América Latina globalizada", en Luzón Peña, Diego-Manuel et al. (dirs.), Documentos penales y criminológicos (DPC), vol. I, Hispamer, 2001, pp. 555-568.

GALEANO, Eduardo, Patas Arriba. La Escuela del Mundo al Revés, México, Siglo XXI, 1999,

GÓMEZ COLOMER, J.L., "Adversarial system, proceso acusatorio y principio acusatorio: una reflexión sobre el modelo de enjuiciamiento criminal aplicado en los Estados Unidos”, Revista Poder Judicial, 2006, no. especial XIX, pp. 25-77.

JIMENO-BULNES, M., “American criminal procedure in a european context”, Cardozo journal of international and comparative law, vol. 21.3, primavera de 2013, pp. $410-$ 459.

LANGBEIN, JOHN H., "Tortura y plea bargaining”, en Mayer, Julio y Bovino, Alberto (comps.), El procedimiento abreviado, Buenos Aires, Del Puerto, 2001. 
PÉREZ BALTODANO, Andrés, "El futuro de las identidades políticas de América Latina", Confidencial. Semanario de Información y Análisis, no. 233, 2001,

Programa de Naciones Unidas para el Desarrollo. Seguridad Jurídica e Inversiones. Acceso a la Justicia en Centroamérica y Panamá, San José, Costa Rica, 2000.

Proyecto Estado de la Región - Programa de Naciones Unidas para el Desarrollo. Segundo Informe sobre Desarrollo Humano en Centroamérica y Panamá. Proyecto del Estado de la Región, San José, Costa Rica, 2003, pp. 282-304.

Segundo Informe sobre Desarrollo Humano en Centroamérica y Panamá. Resumen del Capítulo 7: El Desafío de la Democratización de la Justicia y del Fortalecimiento de la Rendición de Cuentas. San José, Costa Rica 2003: http://www.estadonacion.or.cr/ Region2003/Paginas/prensa/Resumen-7.pdf

Memoria de la Sala de lo Penal de la Corte Suprema de Justicia (1996-20oo), Managua, Corte Suprema de Justicia de la República de Nicaragua, 2001.

MONTERO AROCA, J., "Principio acusatorio y prueba en el proceso penal. La inutilidad jurídica de un eslogan político", en Gómez Colomer J.L. (coord), Prueba y proceso penal, Valencia, Tirant lo Blanch, 2008, pp. 17-66.

UMAÑA, Mario, "Inversión Extranjera Directa en Centro América: el rol de la seguridad jurídica", Marzo, 2002, p. 22. Documento en proceso, recuperado de: $h t t p: / / w w w$. incae.edu/es/clacds/publicaciones/pdf/cen443.pdf

ZAFFARONI, Raúl y MADLENER, Kurt, La Justicia como garante de los derechos humanos: La independencia del Juez, San José, Costa Rica, ILANUD, 1996, pp. 5-37.

ZAFFARONI, Raúl, "El Curso de la Criminología", Revista de la Asociación de Ciencias Penales de Costa Rica, no. 18, 2000, pp. 7-11.

"Los derechos fundamentales en la instrucción penal en los países de América Latina”, en Zaffaroni, Raúl y Carranza, Elías (coords.), México, 2007.

"América Latina: Análisis regional, proceso penal y derechos humanos: Códigos, principios y realidad", en Luzón Peña, Diego-Manuel et al. (dirs.), Documentos penales y criminológicos (DPC), vol. I, Hispamer, 2001, pp. 339-362.

"Proceso Penal y Derechos Humanos: Códigos, Principios y Realidad", El Proceso Penal. Sistema Penal y Derechos Humanos, México, Porrúa, 200o, pp. 3-24.

"La justicia como garante de los derechos humanos en México y en América Central: La independencia del Juez", La Justicia como garante de los Derechos Humanos: La independencia del juez, San José, Costa Rica, ILANUD, 1996, pp. 5-37. 